\title{
Biochemical genetics: From mechanisms to diagnosis and management of genetic disease
}

Antonio Velázquez, $M D, P h D$

On March 9, 2000, for the first time, the Society for Inherited Metabolic Disorders (SIMD) presented a special symposium at the Annual Clinical Genetics Meeting of the ACMG. The SIMD is the scientific and professional organization that attracts investigators, clinicians, and nutritionists dedicated to the study and management of inborn errors of metabolism in North America (as well as some from the rest of the world).

Medical genetics has experienced many changes since it became of age in the 1960s. The great strides in human molecular genetics have enormously increased the understanding of Mendelian diseases, and the capacities for their diagnosis. However, effective therapeutic approaches have lagged behind. Gene therapy will eventually provide the definitive cure for most of these disorders, but it has become painfully clear that this will not be achieved in the near future. At the same time, the great progress that has been made in the knowledge of the biochemical and metabolic derangement of inherited diseases has led to an increasing number of diseases for which prevention and treatment are available. Although in the past there has been insufficient communication between practitioners of the traditional specialties of medical genetics, such as cytogenetics and dysmorphology, and those interested in inherited metabolic diseases, the dividing line between them has been blurring lately, as evidenced by the recent increase in the scope of the last (8th) edition of The Metabolic and Molecular Basis of Inherited Disease.' The advances provided by positional cloning and by genomics, no matter how spectacular they have

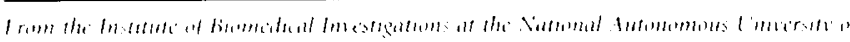

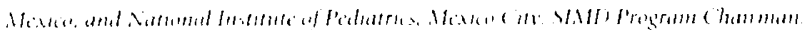

been, has not resulted in similar progress in the understanding of the pathophysiology of genetic disease. As the mutational range of Mendelian diseases has been described, the hope for a strong correlation between genotype and phenotype has largely vanished. ${ }^{2}$ It is, therefore, urgent to make significant inroads into the biochemical and metabolic foundations of these disorders.

The objective of this session was to evidence this assertion by considering some areas in the study of inherited metabolic disorders that illustrate the state of the art in some fields of biochemical genetics. The first presentation, with emphasis on genotype-phenotype relations, showed how enlightening and powerful, and at the same time how limiting, the joint knowledge of the molecular genotype and of the biochemical disturbances can be. The second presentation, on an exploding new area of congenital disorders of glycosylation, is a model for the future understanding and management of most genetic diseases. The study of fatty acid oxidation defects has been a burgeoning field in the past 2 decades. However, many affected patients are still not diagnosed and/or adequately treated. The third presentation, considering these disorders, demonstrated how a thorough biochemical (and not only molecular!) analysis can empower the diagnostic challenges of many illnesses.

For the SIMD, this symposium at the ACMG annual meeting represented a historic milestone. We look forward to an increasing communication and collaboration with our medical genetics colleagues that will not only be enlightening to both of our organizations but especially will be valuable to our patients.

\section{References}

1. Scriver C, Beaudet AL, Sly WS, Vogelstein B, Kinzler KW, Valle D, Childs B. The metabolic and molecular basis of inherited disease, 8 th ed. New York: McGraw-Hill, 2000 .

2. Dipple KM, MiCabe ER. Phenotypes of patients with "simple" Mendelian disorders are complex traits: thresholds, modifiers, and systems dynamics. Am J Hum Genet 2000;66:1729-1735. 